\title{
Prediction of Physical Parameters of Pumpkin Seeds Using Neural Network
}

\author{
Bunyamin DEMIR ${ }^{1 *}$, Ikbal ESKI ${ }^{2}$, Zeynel A. KUS ${ }^{3}$, Sezai ERCISLI ${ }^{4}$ \\ ${ }^{1}$ Mersin University, Vocational School of Technical Sciences, Department of Mechanical and Metal Technologies, 33343, Mersin, \\ Turkey; demir_33@hotmail.com (*0rrespondingauthor) \\ ${ }^{2}$ Erciyes University, Faculty of Engineering, Department of Mechatronics Engineering, 38039, Talas, Kayseri, Turkey; ikbal@erciyes.edu.tr \\ ${ }^{3}$ Erciyes University, Faculty of Agriculture, Department of Biosystems Engineering, 38280, Talas, Kayseri, Turkey; zkus@erciyes.edu.tr \\ ${ }^{4}$ Ataturk University, Faculty of Agriculture, Department of Horticulture, 25240, Erzurum, Turkey; sercisli@atauni.edu.tr
}

\begin{abstract}
The design of the machines and equipment used in harvest and post-harvest processing should be compatible with the physical, mechanical and rheological characteristics of the fruits and vegetables. In machine design for agricultural products, several characteristics of relevant products and seeds should be known ahead. Designers can either measure all these design parameters one by one, or they may use intelligent systems to estimate such parameters. Neural networks (NNs) are new computational tools that provide a quick and accurate means of physical properties prediction of agricultural materials, and have been shown to perform well in comparison with traditional methods. In this research, some physical properties of pumpkin (Cucurbita pepo L.) seeds, including linear dimensions, volume, surface and projected area, geometric mean diameter and sphericity were calculated tridimensional in lab conditions. Then, prediction of these parameters was carried out using NNs. The research was divided into two parts; experimental investigation and simulation analysis with NNs. Back Propagation Neural Network (BPNN) and Radial Basis Neural Network (RBNN) structures were employed to estimate physical parameters of the pumpkin seeds. The Root Mean Squared Error (RMSE) was 0.6875 for BPNN and 0.0025 for RBNN structures. The RBNN structure was superior in prediction and could be used as an alternative approach to conventional methods.
\end{abstract}

Keywords: agricultural products, computational system, Cucurbita pepo L., physical properties, prediction

\section{Introduction}

Pumpkin belongs to Cucubitaceae family (Taylor and Brant, 2002; Call, 2006). The majority of the species in this family are found in five genera. The genus Cucurbita includes five species: C. maxima, C. pepo, C. moschata, C. ficifolia, and $C$. turbaniformis in which $C$. pepo exhibits the widest variation (Gemrot et al., 2006; Ardabili et al., 2011).

Determination of the physical attributes of agricultural products is very significant for design of post-harvesting technologies and prediction of some essential parameters and characteristics correctly (Mohsenin, 1986). Physical attributes like geometric mean diameter, sphericity, grain trajectory, surface area, grain volumetric and specific weight, density, porosity and colour are used to design processes and equipment for product processing, transportation, screening, storage and drying-like processes (Tabatabaeefar and Rajabipour, 2005). In addition, determination of the physical attributes is used in terms of the final product quality evaluation and classification of different types (Taner et al., 2015). It also allows planning and controlling the above processes and gives a possibility of selecting parameters to functioning of devices and machines (Kaliniewicz et al., 2014). The information on the size and forms of farming components is essential to plan sizing, harvesting, separation, planting and handling devices (Sahay and Singh, 2004). Design of pneumatic separation devices requires surface and projected area (Bwade and Aliyu, 2012).

NNs have been used in various disciplines like hydrology (Aksoy and Mohammadi, 2016), renewable and sustainable energy (Ata, 2015), robotics and computer-integrated manufacturing (Chen and Wang, 2016), robotics and autonomous systems (Woodford et al., 2017). Some application areas in agriculture are data prediction (Štastný et al., 2011), classification of agricultural products (Shahin et al., 2002; Khalesi et al., 2012; Dousti et al., 2013; Reshadsedghi et al., 2014), food and crop analysis (El-Sanhoty et al., 2006; Monteiro et al., 2007), drying process (Khazaei et al., 2013), precise weed detection and weed seeds identification (Granitto 
et al., 2002; Nebot et al., 2012), agricultural crop yield prediction (Dahikar et al., 2014), agricultural economics (Chen, 2005; Rohani et al., 2011), data analysis tool in precision agriculture (Irmak et al., 2006).

In this paper, two NN structures were used in prediction of some physical parameters of pumpkin seeds, especially linear dimensions, geometric mean diameter, sphericity, volume, surface and projected area and consequently the performance of these structures was compared.

\section{Materials and Methods}

\section{Seeds measurements}

The pumpkin (Cucurbita pepo L.) seeds, grown in summer season of the year 2015, used in this study were obtained from the province of Kayseri, Turkey. The seeds were selected manually and cleaned free of dirt, broken ones and other foreign materials.

The moisture content of the seeds was determined by following a dry basis method (Suthar and Das, 1996) and was found to be $4.29 \%$ d.b. Measurements of the seeds were carried out at this moisture content. A total 100 seeds were selected randomly. The three main perpendicular dimensions, length $(L$, $\mathrm{mm})$, width $(W, \mathrm{~mm})$ and thickness $(T, \mathrm{~mm})$, were measured (see Fig. 1) with a digital caliper $( \pm 0.01 \mathrm{~mm})$.

The geometric mean diameter $\left(D_{g}, \mathrm{~mm}\right)$ and sphericity $(\phi)$ were calculated by the equations below given by Mohsenin (1986) and cited by Vishwakarma (2012):

$$
\begin{aligned}
& D_{g}=(L W T)^{1 / 3} \\
& \phi=\frac{D_{g}}{L} \times 100
\end{aligned}
$$

The shape index $(S I)$ was calculated by the following equation cited by Sayınc1 et al. (2015):

$$
S I=\frac{2 L}{(W+T)}
$$

The surface area $\left(S, \mathrm{~mm}^{2}\right)$ was obtained by equation below given by McCabe et al. (1986) and cited by Arslan and Vursavus (2008):

$$
S=\pi D_{g}^{2}
$$

The volume $\left(V, \mathrm{~mm}^{3}\right)$ and projected area $\left(A_{p}, \mathrm{~mm}^{2}\right)$ of the seed were calculated by the following equations cited by Khazaei et al. (2006), Afonso Junior et al. (2007):

$$
\begin{aligned}
& V=\frac{\pi}{6} D_{g}^{3} \\
& A_{p}=\frac{\pi}{4} D_{g}^{2}
\end{aligned}
$$

Calculated parameters of the pumpkin seeds were used in the training process of two different $\mathrm{NN}$ structures. These structures are back-propagation neural network and radial basis function $\mathrm{NN}$ algorithms.
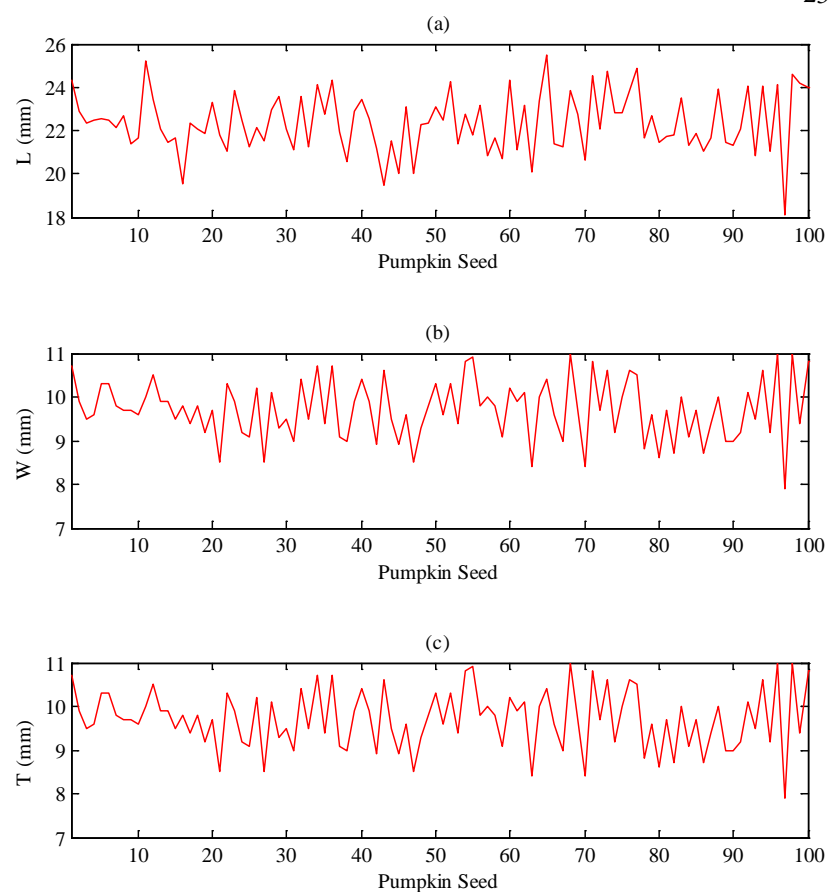

Fig. 1. Three main dimensions of pumpkin seeds; (a) length, (b) width, (c) thickness

\section{Neural Networks}

In this investigation, feed forward neural network model was applied to estimate some physical parameters of pumpkin seeds. Fig. 2 presents schematic illustration of neural network predictor.

$$
z_{k}=g\left[\sum_{f=1}^{3} \sum_{j=1}^{8} w_{f} f_{t}+b_{j}\right]
$$

where $f_{\mathrm{j}}$ is the output of the $j^{\text {th }}$ neuron, $w_{i j}$ is the weight of the relation between the input and hidden layer neurons, $b_{j}$ is the bias of the $j^{\text {th }}$ neuron in the hidden layer. The function $g($.$) is$ named as the hidden layer transfer function. The network output signal can be described in the following design:

$$
y_{j}=g\left[\sum_{j=1}^{8} \sum_{k=1}^{6} w_{j k} z_{k}+b_{k}\right]
$$

where $\mathrm{w}_{\mathrm{jk}}$ are the weights between $j^{\text {th }}$ neurons and $k^{\text {th }}$ neurons, $b_{k}$ is the bias of the $k^{\text {th }}$ neurons in the output layer (Soylak et al. 2015). Two learning algorithms which are applied to predict parameters of pumpkin seeds, concisely depicted in the bellowing subdivisions. During the analysis, NeuralWorks Professional II/Plus software was used.

\section{Back Propagation Neural Network}

The BPNN is a type of multi-layered feed forward network. The BPNN is composed of at least three layers every time: input

layer, hidden layer/layers and output layer. The BPNN is generally employed to revise the weights of the BPNN. The weights between input and hidden layer are revised as follows:

$$
\Delta w_{t j}(t)=-\eta \frac{\partial E_{2}(t)}{\partial w_{t j}(t)}+\alpha \Delta w_{t j}(t-1)
$$

The weights between the hidden and output layer are revised in the following function:

$$
\Delta w_{j k}(t)=-\eta \frac{\partial E_{1}(t)}{\partial w_{j k}(t)}+\alpha \Delta w_{j k}(t-1)
$$

where $\eta$ is the learning coefficient, and $\alpha$ is the momentum coefficient, $E_{2}(t)$ is the propagation error and $E_{1}(t)$ is the error between calculated and BPNN output signals. 


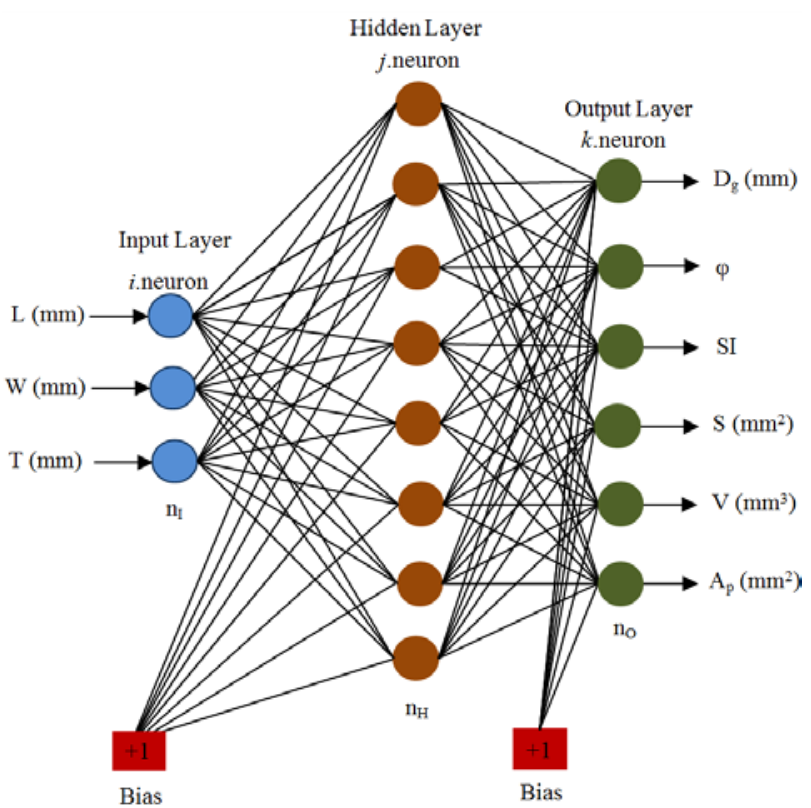

Fig. 2. Schematic representation of neural network predictor

\section{Radial Basis Function Neural Network}

RBNN with a hidden layer are able to perform universal approximation. The hidden layer consists of Gaussian equation modules. The Gaussian equation, $\psi(i)$ is determined as the following function (Ylldirım et al., 2013):

$$
\psi_{i}=\exp \left[-\frac{\left\|x-c_{i}\right\|_{1}}{\sigma_{i}^{2}}\right]
$$

where $\boldsymbol{x}$ is the vector of an input sample, $c_{i}$ is the vector of the centre of the $i^{\text {th }}$ module and $\sigma_{i}^{2}$ is the variance of the $l^{\text {th }}$ module. The output layer integrates the Gaussian domains produced by the hidden modules. The output signal of the $m^{\text {th }}$ module, $r_{j}$, is determined with the following function:

$$
r_{m}=\sum_{l}^{n} w_{l m} \psi_{l}
$$

where $w_{l m}$ is the weight from the $l^{\text {th }}$ module to the $m^{\text {th }}$ output module.

\section{Results and Discussion}

Results of the BPNN structure used in prediction of the average geometric diameter and sphericity of the pumpkin seeds are presented in Fig. 3. The error values of the BPNN predictor were quite high. Results of the BPNN structure used in prediction of the shape index and surface area of the pumpkin seeds are provided in Fig. 4. The results of the predictor were not good enough. The last physical properties for which the BPNN structure used as a predictor were volume and projected area (see Fig. 5). As seen in Fig. 3, 4 and 5, the BPNN algorithm was not a useful tool to predict the physical parameters of pumpkin seeds. BPNN structure has a quite slow learning ability. Since this NN structure try to reduce the errors from output to input, the learning is quite slow due to the back propagation. BPNN structure usually found to be insufficient in estimation of seed physical parameters for the same iteration period. Therefore RBNN structure with a different learning algorithm was employed to estimate relevant parameters.

Results for geometric mean diameter and sphericity prediction for this algorithm are given in Fig. 6. As seen in Fig.
6 , results of the RBNN predictor were pretty good. Results for the shape index and surface area prediction for this algorithm are given in Fig. 7, volume and projected area in Fig. 8. According to the simulation results, it is obvious that in prediction of the related physical parameters, the RBNN structure was more successful than the BPNN structure (see Table 1). RBNN structure has some superiority over the other $\mathrm{NN}$ structures such as faster convergence, smaller extrapolation errors, and higher reliabilities. RBNN is a class of single hidden layer feedforward networks where the activation functions for hidden units are defined as radially symmetric basis functions such as the Gaussian function. Thus, the RBNN can be used in prediction of such physical parameters of agricultural production.
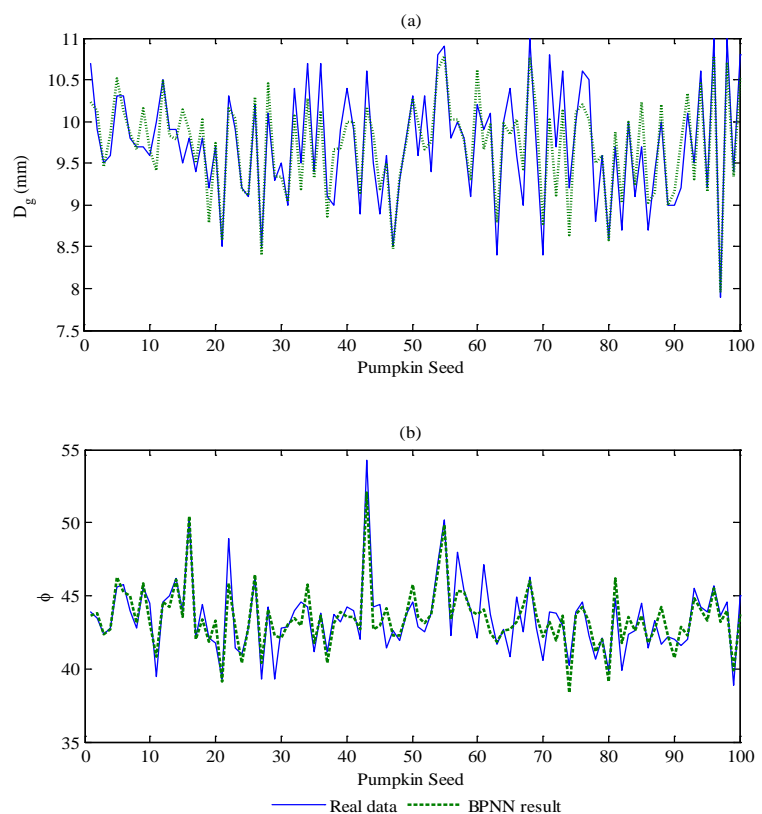

Fig. 3. (a) Experimental and prediction results of geometric mean diameter parameter using the BPNN structure; (b) Experimental and prediction results of sphericity parameter using the BPNN structure 

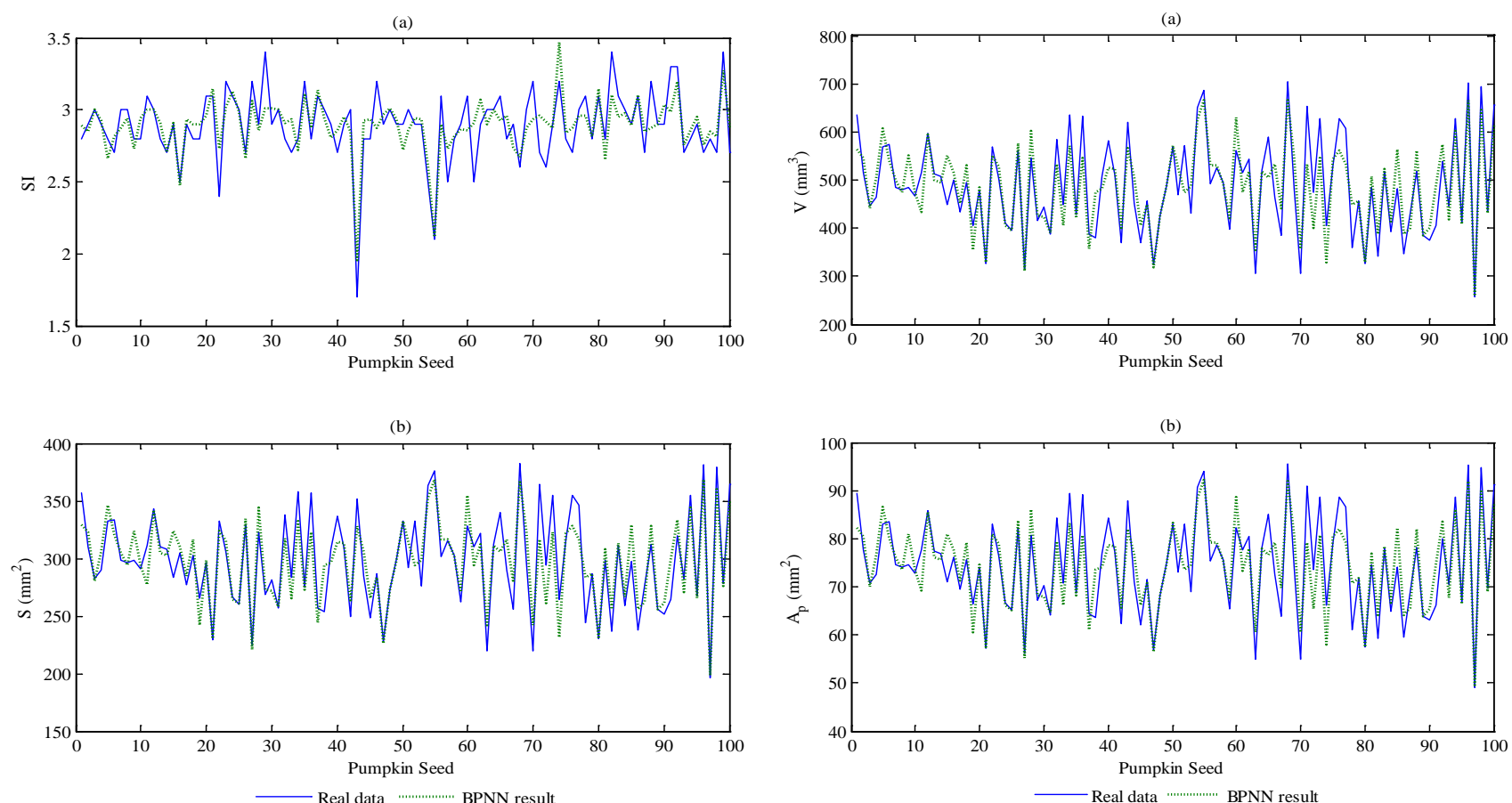

Fig. 4. (a) Experimental and prediction results of shape index parameter using the BPNN structure; (b) Experimental and prediction results of surface area parameter using the BPNN structure
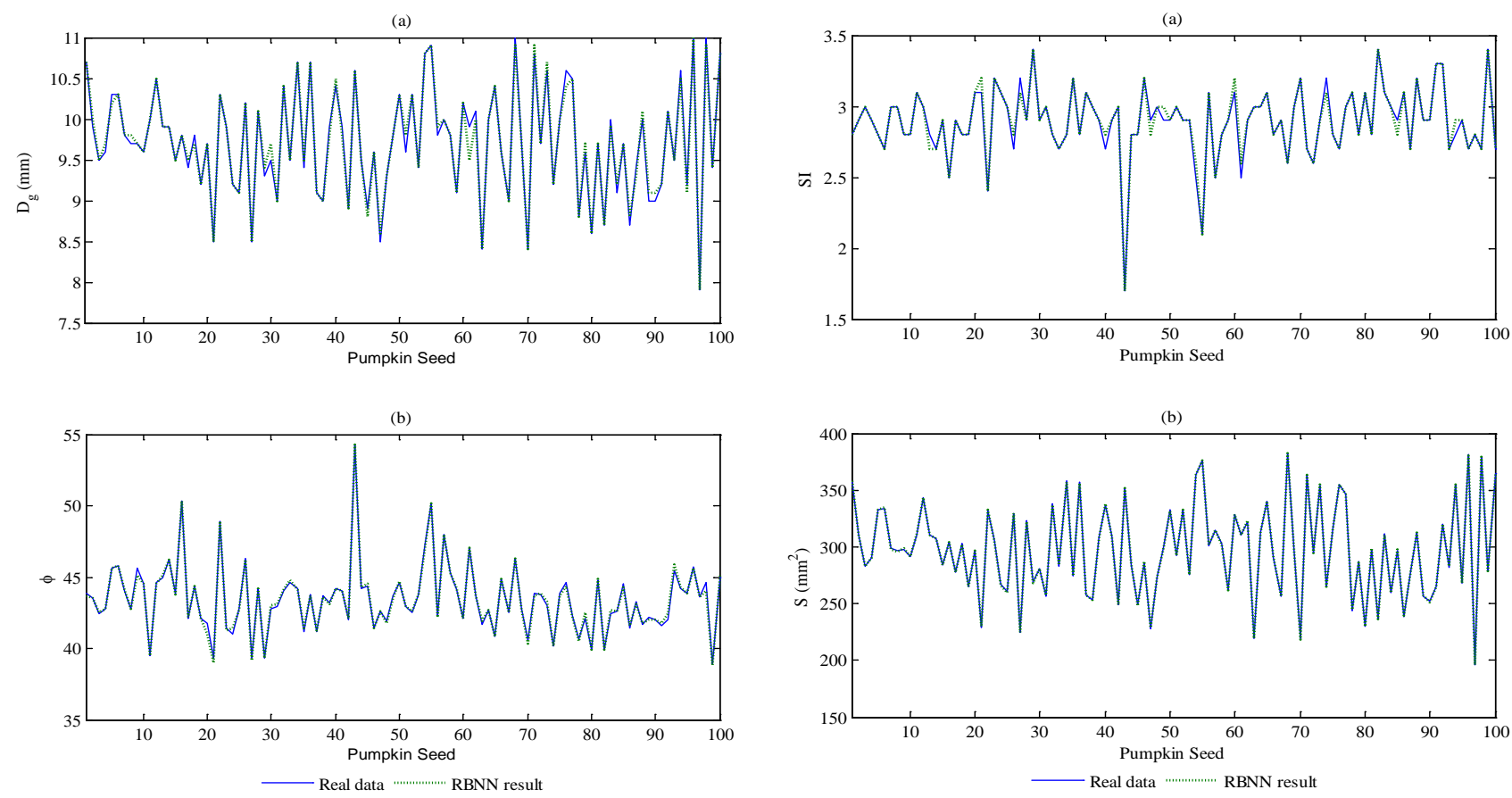

Fig. 6. (a) Experimental and prediction results of geometric mean diameter parameter using the RBNN structure; (b) Experimental and prediction results of sphericity parameter using the RBNN structure

Fig. 5. (a) Experimental and prediction results of volume parameter using the BPNN structure; (b) Experimental and prediction results of projected area parameter using the BPNN structure

Fig. 7. (a) Experimental and prediction results of shape index parameter using the RBNN structure; (b) Experimental and prediction results of surface area parameter using the RBNN structure 
Table 1. Neural network parameters of the BPNN and RBNN structure

\begin{tabular}{ccc}
\hline Neural Network Type & BPNN & RBNN \\
\hline Learning rule & $\Delta w_{j k}(t)=-\eta \frac{\partial E_{1}(t)}{\partial w_{j k}(t)}+\alpha \Delta w_{j k}(t-1)$ & $y(x)=\sum_{j=1}^{m} w_{j} \exp \left(-\sum_{k=1}^{n} \frac{\left(x_{k}-c_{j k}\right)^{2}}{r_{j k}^{2}}\right)$ \\
$\eta$ (Learning Rate) & 0.2 & 0.2 \\
$\alpha$ (Momentum Term) & 0.3 & 0.3 \\
$\mathrm{~N}$ (Iteration Number) & 10000000 & 10000000 \\
$\mathrm{n}_{\mathrm{I}}$ (Input Layer Neurons) & 3 & 3 \\
$\mathrm{nH}_{\mathrm{H}}$ (HiddenLayer Neurons) & 8 & 8 \\
$\mathrm{no}$ (Output Layer Neurons) & 6 & 6 \\
$\mathrm{~g}($.$) (Transfer Function)$ & sigmoid & sigmoid \\
RMSEs (Errors) & 0.6875 & 0.0025 \\
\hline
\end{tabular}

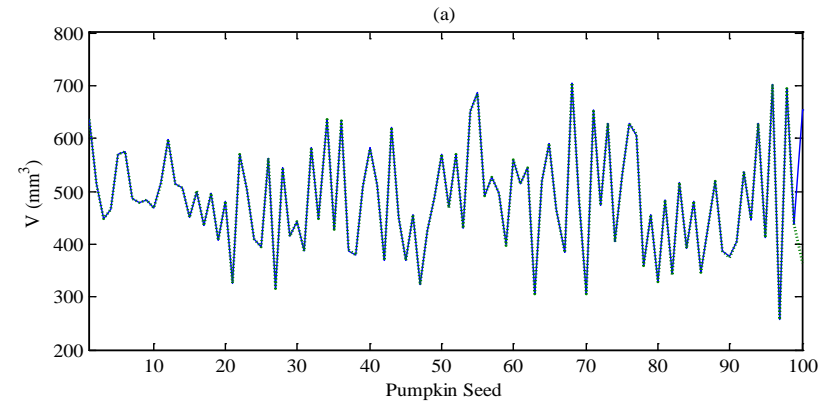

(b)

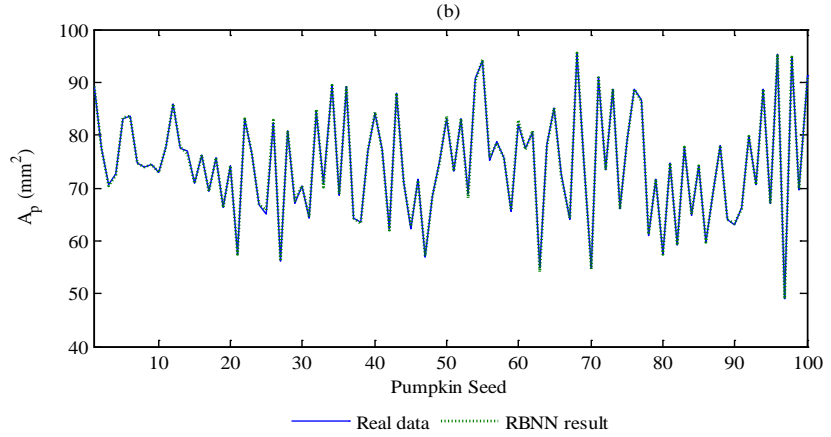

Fig. 8. (a) Experimental and prediction results of volume parameter using the RBNN structure; (b) Experimental and prediction results of projected area parameter using the RBNN structure

Similar to the results of the present research, the high performance of different NN structures in prediction or estimation of agricultural objectives was reported by Alvarez (2009), Dai X et al. (2011), Khoshnevisan et al. (2014), Rad et al. (2015), Taner et al. (2015), Shafaei et al. (2016).

\section{Conclusions}

Working with too many samples is both a time-consuming and a costly process. It also brings together various measurement errors. Right at this point, NNs can provide a great alternative to overcome such time-consuming, costly and erroneous processes. Therefore, NN structures were employed to estimate physical characteristics of pumpkin seeds from easily identified characteristics. In this study, some physical parameters of pumpkin seeds were predicted by two different NN structures. The RBNN had superior performance to predict different physical parameters of the pumpkin seeds. RBNN have some advantages also as of: they minimize the possibility of error and hence the hypothesis of linear behaviour is no longer required. RBNN structure of the present study provided high-accuracy outcomes and also great time and cost savings. For that reason, the RBNN could be employed to predict such physical parameters in agricultural applications.

\section{References}

Afonso Junior PC, Correa PC, Pinto FAC, Queiroz DM (2007). Aerodynamic properties of coffee cherries and beans. Biosystems Engineering 98:39-46.

Aksoy H, Mohammadi M (2016). Artificial neural network and regression models for flow velocity at sediment incipient deposition. Journal of Hydrology 541:1420-1429.

Alvarez R (2009). Predicting average regional yield and production of wheat in the Argentine Pampas by an artificial neural network approach. European Journal of Agronomy 30(2):70-77.

Ardabili AG, Farhoosh R, Khodaparast MHH (2011). Chemical composition and physicochemical properties of pumpkin seeds (Cucurbita pepo subsp.pepo var. Styriaka) Grown in Iran. Journal of Agricultural Science and Technology 13:1053-1063.

Arslan S, Vursavus KK (2008). Physico-mechanical properties of almond nut and its kernel as a function of variety and moisture content. The Philippine Agricultural Scientist 91:171-179.

Ata $R$ (2015). Artificial neural networks applications in wind energy systems: a review. Renewable and Sustainable Energy Reviews 49:534-562.

Bwade KE, Aliyu B (2012). Investigations on the effect of moisture content and variety factors on some physical properties of pumpkin seed (Cucurbitaceae spp). International Journal of Engineering, Business and Enterprise Applications (IJEBEA) 3(1):20-24.

Call F, Huan S, Quanhong L (2006). A review on pharmacological activities an utilization technologies of pumpkin. Plant Foods for Human Nutrition 61:73-80.

Chen J (2005) Neural Network Applications in Agricultural Economics. Doctoral Dissertation University of Kentucky.

Chen T, Wang YC (2016). Estimating simulation workload in cloud manufacturing using a classifying artificial neural network ensemble approach. Robotics and Computer - Integrated Manufacturing 38:42-51. 
Dahikar SS, Rode SV (2014). Agricultural crop yield prediction using artificial neural network approach. International Journal of Innovative Research in Electrical, Electronics, Instrumentation and Control Engineering2(1):683-686.

Dai X, Huo Z, Wang H (2011). Simulation for response of crop yield to soil moisture and salinity with artificial neural network. Field Crops Research 121(3):441-449.

Dousti A, Ghazavi MA, Maleki A (2013). Grading of empty walnut using signal processing and artificial neural network techniques. International Journal of Agriculture and Crop Sciences 6(15):1072-1078.

El-Sanhoty R, Shahwan T, Ramadan MF (2006). Application of artificial neural networks to develop a classification model between genetically modified maize (Bt-176) and conventional maize by applying lipid analysis data. Journal of Food Composition and Analysis 19(6):628636.

Gemrot F, Barouh N, Vieu JP, Pioch D, Montet D (2006). Effect of roasting on tocopherols of gourd seeds (Cucurbita pepo). Grasas y Aceites 57(4):409-414.

Granitto PM, Navone HD, Verdes P F, Ceccatto HA (2002). Weed seeds identification by machine vision. Computers and Electronics in Agriculture 33(2):91-103.

Irmak A, Jones JW, Batchelor WD, Irmak S, Boote KJ, Paz JO (2006). Artificial neural network model as a data analysis tool in precision farming. Transactions of the ASABE 49(6):2027-2037.

Kaliniewicz Z, Jadwisieńczak K, Choszcz D, Kolankowska E, Przywitowski M, Śliwiński D (2014). Correlations between germination capacity and selected properties of parsnip seeds (Pastinaca sativa L.). Agricultural Engineering 1(149):39-49.

Khalesi S, Mahmoudi A, Hosainpour A, Alipour A (2012). Detection of walnut varieties using impact acoustics and artificial neural networks (ANNs). Modern Applied Science 6(1):43-49.

Khazaei J, Sarmadi M, Behzad J (2006). Physical properties of sunflower seeds and kernels related to harvesting and dehulling. Lucrari Stiintifice 49:262-271.

Khazaei NB, Tavakoli T, Ghassemian H, Khoshtaghaza MH, Banakar A (2013). Applied machine vision and artificial neural network for modeling and controlling of the grape drying process. Computers and Electronics in Agriculture 98:205-213.

Khoshnevisan B, Rafiee S, Omid M, Mousazadeh H (2014). Development of an intelligent system based on ANFIS for predicting wheat grain yield on the basis of energy inputs. Information Processing in Agriculture 1(1):1422.

McCabe WL, Smith JC, Harriot P (1986). Unit operations of chemical engineering. McGraw-Hill Book Co., New York.

Mohsenin NN (1986). Physical Properties of Plant and Animal Materials. Structure, Physical Characteristics and Mechanical Properties. Gordon and Breach Science Publishers, New York.

Monteiro ST, Minekawa Y, Kosugi Y, Akazawa T, Oda K (2007). Prediction of sweetness and amino acid content in soybean crops from hyperspectral imagery. ISPRS Journal of Photogrammetry and Remote Sensing 62(1):2-12.

Nebot P, Torres-Sospedra J, Recatala G (2012). Using neural networks for maintenance tasks in agriculture: precise weed detection. Proceedings of the International Conference of Agricultural Engineering CIGRAgeng.

Rad MRN, Fanaei HR, Rad MRP (2015). Application of artificial neural networks to predict the final fruit weight and random forest to select important variables in native population of melon (Cucumis melo L.). Scientia Horticulturae 181:108-112.

Reshadsedghi A, Mahmoudi A, Azimirad V, Hajilou J, Ghaffari H (2014). Non-Destructive detection of unshelled almonds quality based on their kernel percentage using impact-acoustics and ANN's techniques. Agriculture Science Developments 3(11):360-365.

Rohani A, Abbaspour-Fard MH, Abdolahpour S (2011). Prediction of tractor repair and maintenance costs using artificial neural network. Expert Systems with Applications 38(7):8999-9007.

Sahay KM, Singh KK (2004). Unit operations of agricultural processing. Vikas Publishing House PVT LTD.

Sayıncı B, Ercişli S, Akbulut M, Şavşatli Y, Baykal H (2015). Determination of shape in fruits of cherry laurel (Prunus laurocerasus) accessions by using elliptic Fourier analysis. Acta Scientiarum Polonorum Hortorum Cultus 14(1):63-82.

Shafaei SM, Nourmohamadi-Moghadami A, Kamgar S (2016). Development of artificial intelligence based systems for prediction of hydration characteristics of wheat. Computers and Electronics in Agriculture 128:34-45.

Shahin MA, Tollner EW, Gitaitis RD, Sumner DR, Maw BW (2002). Classification of sweet onions based on internal defects using image processing and neural network techniques. Transactions-American Society of Agricultural Engineers 45(5):1613-1618.

Soylak M, Oktay T, Turkmen I (2015). A simulation-based method using artificial neural networks for solving the inverse kinematic problem of articulated robots. Proceedings of the Institution of Mechanical Engineers, Part E: Journal of Process Mechanical Engineering 0954408915608755 .

Štastný J, Konečný V, Trenz O (2011). Agricultural data prediction by means of neural network. Agricultural Economics-Czech 57(7):356361.

Suthar SH, Das SK (1996). Some physical properties of karingda [Citrullus lanatus (Thumb) Mansf] seeds.Journal of Agricultural Engineering Research 65(1):15-22

Tabatabaeefar A, Rajabipour A (2005). Modeling the mass of apples by geometrical attributes. Scientia Horticulturae 105(3):373-382.

Taner A, Tekgüler A, Sauk H (2015). Classification of durum wheat varieties by artificial neural networks. Anadolu Journal of Agricultural Sciences 30:51-59.

Taylor MJ, Brant J (2002). Trends in world cucurbit production, 1991 to 2001. In: Maynard DN (Ed). Cucurbitaceae. Alexandria, VA: ASHS Press pp 373-379.

Vishwakarma RK, Shivhare US, Nanda SK (2012). Physical properties of guar seeds. Food and Bioprocess Technology 5(4):13641371.

Woodford GW, Plessis MC, Pretorius CJ (2017). Concurrent controller and simulator neural network development for a snake-like robot in evolutionary robotics. Robotics and Autonomous Systems 88:37-50.

Yıldırım Ş, Eski İ, Polat Y (2013). Design of adaptive neural predictor for failure analysis on hip and knee joints of humans. Neural Computing and Applications 23:73-87. 